\title{
PREDICTION OF BIOAVAILABILITY OF CHLORPYRIFOS RESIDUES IN SOIL TO EARTHWORMS
}

\author{
X.M. Wu ${ }^{1}$, Y.L. Yu ${ }^{2 *}$, M. Li ${ }^{1}$, Y.H. Long ${ }^{1}$, H. Fang ${ }^{2}$ and S.N. Li $^{2}$ \\ ${ }^{1}$ Department of Plant Protection, Agriculture College, Guizhou University, Xiahui Road 14, \\ Huaxi District Guiyang 550025, People's Republic of China. ${ }^{2}$ Department of Plant Protection, \\ College of Agriculture and Biotechnology, Zhejiang University, Kaixuan Road 268, Huajiachi \\ Campus Hangzhou 310029, People's Republic of China. \\ *Corresponding author: agr.xmwu@gzu.edu, ylyu@gzu.edu.cn
}

\begin{abstract}
An incubation test was conducted to investigate the effect of aging on bioavailability of chlorpyrifos in soil and to assess the feasibility of chemical extraction techniques for predicting bioavailability of chlorpyrifos in soil. Chlorpyrifos was spiked into sterilized soil and aged in microcosms for up to 120 days. The earthworms were incubated in the spiked soils, at $0,7,14,30,60$, and 120 days after spiking, for a period of 7 days. After exposure, chlorpyrifos concentrations in the earthworm tissues were determined. Change in chemical extractability of soil-chlorpyrifos was measured using a several solvent systems including methanol, methanol-water (9:1), acetone-water (5:3), and water. The results show that chemical extractability and earthworm bioavailability of chlorpyrifos in soil decreased with aging. The amount of aged and unaged chlorpyrifos recovered from soil varied with the individual chemical extractant and extraction method. Concentrations of chlorpyrifos in Eisenia foetida were significantly higher than in Allolobophora caliginosa, suggesting that the bioavailability of chlorpyrifos was a species-dependent process. The extractability of chlorpyrifos by chemical solvents was significantly correlated with bioavailability fraction of E. foetida and A. caliginosa, showing that these extraction techniques may be efficient for predicting bioavailability of chlorpyrifos in soil.
\end{abstract}

Keywords: Chlorpyrifos, residue, soil, earthworm, bioavailability, prediction.

\section{INTRODUCTION}

Toxic organic chemicals entering soil environments may be subjected to number of processes such as volatilization, leaching, chemical and biological degradation. In addition, sorption and transport-related processes may cause the toxicants to become progressively less bioavailable than ones freshly added to soil. This phenomenon could obviously be observed in the cases of the availability of pesticides such as atrazine (Kelsey et al., 1997), dieldrin (Morrison et al.,2000), butachlor and myclobutanil (Yu et al., 2005), hexachlorobenzene (HCB) (Gao,2009), and DDT, DDE and DDD (Morrison et al., 2000; Fang et al., 2010), phthalate congeners (e.g., di-n-butyl phthalate (DBP) and di-(2-ethylhexyl) phthalate (DEHP) (Hu et al., 2005), and polycyclic aromatic hydrocarbons(PAHs) 
(Kelsey et al., 1997; Johnson et al., 2002; Tang et al., 2002) to earthworms, and the biodegradability of 4-nitrophenol (Hatzinger and Alexander, 1995), atrazine and phenanthrene (Kelsey et al., 1997; Chung and Alexander, 1998) by bacteria. The time-dependent decline in bioavailability has been termed aging (Hatzinger and Alexander, 1995). The potential of ageing to influence the bioavailability of toxicants in a soil matrix is extremely important in relation to biotic uptake, toxicity or biodegradation (Alexander, 2000; Reid et al., 2000a). At present, environmental risk of toxic organic chemicals is based on the total amount of these chemicals in the soil. However, current procedures for analyzing organic pollutants that have persisted in soil do not accurately reflect the availability of these toxic chemicals to living organisms including humans. Therefore, there is a need, for regulatory purposes, to develop an assay to assess the bioavailability of toxic contaminants in soil to biota rather than the total amount.

The bioassay is generally believed to serve this purpose, but biological measurements do not have adequate precision for regulatory and they are often time consuming and costly. An alternative has been focused on a chemical or physical assay. Numerous chemical or physical techniques have been developed to measure the bioavailability of organic chemicals in soil in the past twenty years. For example, $\mathrm{C}_{18}$ membrane disks and Tenax TA beads (Tang and Alexander,1999; Tang et al., 2002), supercritical-fluid extraction (SFE) (Hawthorne and Grabanski, 2000), multicolumn system (Zhao and Voice, 2000), accelerated solvent extraction (ASE) (Tao et al., 2004), semipermeable membrane devices (SPMDs) (Menchai et al., 2008), matrix solid-phase microextraction (matrix-SPME)(Trimble et al., 2008; Fang et al., 2010), and nonexhaustive extraction using a variety or combination of organic solvents or other extractants (Kelsey et al., 1997; Tang and Alexander, 1999; Cuypers et al., 2000; Reid et al., 2000b; Tang et al., 2002; Hu et al., 2005; Yu et al., 2005). In general, these techniques may be efficient for predicting bioavailability of certain chemicals in soil. However, the bioavailability of pollutants in soils or sediments was found to be affected by a complex interaction of the biotic and abiotic factors such as physical-chemical properties of the compound, soil characteristics, aging time, and specific species of organisms of concern (Hatzinger and Alexander, 1995; Alexander, 2000; Reid et al., 2000a; Lanno et al., 2004). For regulatory purposes, to establish sound approaches for evaluating the bioavailable level of toxicants to certain species, theses factors should be addressed.

Chlorpyrifos [O, O-diethyl-O-(3, 5, 6trichloro-2-pyridyl) phosphorothioate] is one of the most widely used organophosphate insecticides. It is effective against a broad spectrum of agricultural and household pests. The behaviors of chlorpyrifos in soil were studied intensely due to its long persistence in soil environments and harmful impacts upon organisms (e.g., Racke et al., 1998; Yucel et al., 1999; Singh et al., 2003; Ngan et al., 2005; Fang et al., 2006; Vischetti et al., 2007; Fang et al., 2008; Vejares et al., 2010). Earthworms comprise the largest proportion of the biomass of the soil fauna and contribute to the process of cycling of nutrients in terrestrial ecosystems. They can accumulate soilchemicals and are widely used as bioindictors of soil health and toxicity testing for chemicals (Lanno et al., 2004). 
However, little is known about availability of chlorpyrifos to earthworms. Therefore, in this study the two species of earthworms, the epigeic species E. foetida and endogeic species A.caliginosa, were used as soil model organisms to investigate the effect of aging on bioavailability of chlorpyrifos in soil. The aims of the present study were (i) to characterize the aging-induced changes in extractability and bioavailability of chlorpyrifos in soil and (ii) to examine the species-related differences in availability of chlorpyrifos to earthworms and (iii) to assess the feasibility of using chemical extraction techniques to predict the bioavailability of the target insecticide.

\section{MATERIALS AND METHODS}

\section{Insecticide}

Analytical-grade chlorpyrifos $\quad(99.5 \%$ purity) was purchased from Dima Technology Inc. (USA). Molecular weight, water solubility, and $\log \mathrm{K}_{\mathrm{ow}}$ value of chlorpyrifos is $350.6,2 \mathrm{mg} \mathrm{L}^{-1}$, and 4.7 , respectively.

\section{Earthworms}

Adult E.foetida of equal size ( $0.37 \mathrm{~g}$ ) was purchased from the Institute of Active Substances, Zhejiang University. Adult A.caliginosa (1.16 g each) was manually collected from the soil of agricultural fields in an agricultural field on the Huajiachi Campus, Zhejiang University, Hangzhou, China. Identification of earthworm species was performed according to the methods described by Yan et al. (2000). All earthworms were allowed to acclimatize to laboratory conditions at $20 \pm 2^{\circ} \mathrm{C}$ for at lest 14 days before use.

\section{Soil collection and sample preparation}

Surface soil $(0 \sim 10 \mathrm{~cm})$ used in this study was collected from agricultural fields at Huajiachi Campus, Zhejiang University. Soil was air-dried at room temperature and passed through a sieve of $0.42 \mathrm{~mm}$. Soil sample was then sterilized with $2.5 \mathrm{Mrad}$ of $\gamma$-irradiation from a ${ }^{60} \mathrm{Co}$ source and stored at $20^{\circ} \mathrm{C}$ in the dark. The soil sample was analyzed using the methods described by $\mathrm{Lu}$ (2000) and was found to have the following physical and chemical properties: $\mathrm{pH}\left(\mathrm{H}_{2} \mathrm{O}, 1: 2.5\right)$, 6.77, cation exchange capacity, $10.6 \mathrm{cmol} \mathrm{kg}^{-1}$, and organic matter, clay, sand, and silt content of $3.05 \%, 20.6 \%, 21.53 \%$, and $58.87 \%$, respectively.

\section{Aging of Chlorpyrifos}

Sterile soil samples of $100 \mathrm{~g}$ were weighed into a sterile $250 \mathrm{~mL}$ conical flask. Three groups of 54 flasks were prepared for this study. One group of soil samples were used to monitor the change in chemical extractability of aged and unaged chlorpyrifos in soil. The other two groups were prepared to assess the effect of aging on bioavailability of chlorpyrifos in soil to earthworms. Soil samples were amended with $1 \mathrm{~mL}$ of acetone containing chlorpyrifos to achieve an initial concentration of $5 \mathrm{mg} \mathrm{kg}$. All the chlorpyrifos-spiked soil samples were agitated on a reciprocating shaker for $24 \mathrm{~h}$ to allow the acetone to volatilize and to ensure thorough mixing of insecticide with the soil. Sterilized distilled water was added to adjust the soil moisture level to approximately $80 \%$ of water holding capacity (WHC).The soil was mixed carefully with a stainless steel medicine spoon. The flasks were then covered with aluminum foil and incubated for $0,7,14$, 30,60 , and 120 days in a dark constant 
temperature incubator $\left(20 \pm 2^{\circ} \mathrm{C}\right)$. The flasks were weighed every seven days, and sterile distilled water was added if necessary to keep the moisture level of $80 \%$ WHC.

\section{Chemical extractability of Chlorpyrifos}

To investigate the feasibility of the chemical extraction technique for predicting bioavailability of chlorpyrifos in soil, an exhaustive extraction procedure and the four non-exhaustive or mild extraction approaches were assessed. For exhaustive extraction, triplicate soil subsamples of $10 \mathrm{~g}$, taken from the flasks in which chlorpyrifos had been aged for 0,7 , $14,30,60$, and 120 days, were mixed with anhydrous sodium sulphate, transferred to Soxhlet apparatus and sequentially Soxhlet extracted with $80 \mathrm{~mL}$ methanol on a water bath at $80 \pm 1^{\circ} \mathrm{C}$ for $24 \mathrm{~h}$. After being dehydrated with anhydrous sodium sulphate on a conical funnel, the extracts were concentrated to dryness on a vacuum rotary evaporator at $35^{\circ} \mathrm{C}$. The residues of chlorpyrifos were recovered by rinsing the flask with $5 \mathrm{~mL}$ of petroleum ether. A $2 \mathrm{~mL}$ aliquot of chlorpyrifos petroleum ether solution was taken, passed through a $0.45 \mu \mathrm{m}$ membrane filter and stored in a stoppered glass vial before analysis using a gas chromatograph (GC).

For non-exhaustive or mild extraction, three duplicate soil subsamples $(10 \mathrm{~g})$ of the same aging time were mixed with $50 \mathrm{~mL}$ of methanol, methanol-water $(9: 1, \mathrm{~V}: \mathrm{V})$, acetone-water $(5: 3, \mathrm{~V}: \mathrm{V})$, and water, respectively. The mixture was shaken for $2 \mathrm{~h}$ on a reciprocating shaker at $20 \pm 2^{\circ} \mathrm{C}$ and then filtered on a Büchner funnel. The filter cake was washed twice with additional 20 $\mathrm{mL}$ of corresponding solvent, and filtrates were combined. The filtrates containing methanol and acetone were evaporated on a rotary evaporator to remove corresponding solvents. All water filtrates containing chlorpyrifos were extracted three times using a separalory funnel with 50,30 , and $30 \mathrm{~mL}$ of petroleum ether, respectively. Prior to analysis using GC, the resulting extracts were dehydrated, concentrated, recovered, and filtered as described above. Triplicate additional soil samples of $10 \mathrm{~g}$ were weighed into the individual aluminum tins and placed in a $105^{\circ} \mathrm{C}$ drying oven for $24 \mathrm{~h}$ for moisture content determination.

\section{Bioassay of Chlorpyrifos}

After $0,7,14,30,60$, and 120 days of chlorpyrifos residing in soil, six replicate flasks were removed from the incubator and $10 \mathrm{E}$. foetida and $3 \mathrm{~A}$. caliginosa were introduced carefully into the surface of the soil, respectively. All flasks were covered with aluminum foil bearing 10 holes for ventilation and incubated for a period of 7 days under conditions of $20 \pm 2^{\circ} \mathrm{C}$ and $80 \%$ WHC. The earthworms were active throughout the exposure period. No obviously seeming toxic effect was observed for added insecticide to test organisms. There was a general decrease in fresh weight of $<5 \%$ for individual earthworm. After 7 days of exposure, the earthworms were removed from soil and kept for $24 \mathrm{~h}$ on the moistened filter paper in a culture dish to allow depuration of gut contents, rinsed with sterile water, dried with filter paper, and weighed. The earthworms were sealed in petri dishes and frozen at $-10^{\circ} \mathrm{C}$ for $24 \mathrm{~h}$. The triplicate tissue samples $(2 \mathrm{~g}$, fresh weight) were ground with $10 \mathrm{~g}$ of anhydrous sodium sulphate using a pestle and mortar. The ground mixtures were then transferred to the Soxhlet apparatus and extracted with $80 \mathrm{~mL}$ petroleum ether for $12 \mathrm{~h}$. After dehydration with anhydrous sodium sulphate, the extracts containing chlorpyrifos were 
concentrated, recovered, and filtered as described above for extraction of chlorpyrifos in soil before analysis by GC.

\section{Analysis of Chlorpyrifos}

Analysis of chlorpyrifos was performed using a gas chromatograph (Fuli GC6890). This GC was equipped with a flame photometric detector (FPD) and an AT-2 glass capillary column $(30 \mathrm{~m} \times 0.32 \mathrm{~mm}$ i.d.). Temperatures of injection port, column, and detector were kept at $230^{\circ} \mathrm{C}$, $230^{\circ} \mathrm{C}$, and $250^{\circ} \mathrm{C}$ for detection purpose, respectively. The carrier gas was nitrogen at a constant flow rate of $50 \mathrm{~mL} \mathrm{~min}^{-1}$, the detector gases were air and hydrogen at flow rates of 80 and $120 \mathrm{~mL} \mathrm{~min}^{-1}$, respectively. The injection volume was 1 $\mu L$. Each sample was analyzed twice. The approximate retention time for the analyte of interest was $3.6 \mathrm{~min}$ in this condition.

\section{Recovery study of fortified earthworm samples}

The efficiency of the method was evaluated by spiking the insecticide-free earthworm tissues at four concentration levels of $0.01,0.05,0.5$, and $5 \mathrm{mg} \mathrm{kg}{ }^{-1}$. Three replicates of each recovery assay and the corresponding blank sample were extracted and analyzed as described above. For calibrating GC, a stock solution of chlorpyrifos, $1000 \mathrm{mg} \mathrm{L}^{-1}$, was made by dissolving $0.05 \mathrm{~g}$ chlorpyrifos with $50 \mathrm{~mL}$ acetone in a $50 \mathrm{~mL}$ volumetric flask. The GC system was calibrated using 6 working standard solutions of the insecticide at the concentration levels of $0.01,0.05,1.0$, 2.5, 5, and $10 \mathrm{mg} \mathrm{L}^{-1}$, which were prepared by appropriate dilution of the $1000 \mathrm{mg} \mathrm{L}^{-1}$ stock standard solution with acetone, prior to injection into GC. Each sample was injected in duplicate.

\section{Statistical analysis}

Statistical treatment of the data was performed using SPSS 11.5 statistical software package (SPSS, Inc., Chicago, IL, USA) and Microsoft Excel 2003.The amounts of chlorpyrifos detected in soil and earthworm samples were expressed as $\mathrm{mg} \mathrm{kg}^{-1}$ on the basis of dry and fresh weight, respectively. All data are the means \pm standard deviation (SD). The statistical significance of chlorpyrifos concentration differences in soils and earthworms was assessed with one way analysis of variance (ANOVA) followed by a least significant difference (LSD) test at $p=0.05$. A paired t-test $(p=0.05)$ was used to determine the significance of differences in bioavailability of chlorpyrifos to earthworms. The relationships between extractability of chlorpyrifos and bioavailability were carried out using a linear regression analyses with the least-square method.

\section{RESULTS AND DISCUSSION}

\section{Evaluation of recovery}

A standard calibration curve of chlorpyrifos was constructed by plotting analyte concentrations against peak areas. The corresponding standard curve equation was $\mathrm{y}=68821.0 \mathrm{x}-6667.3$.This analysis procedure had a good reproducibility for the spiked samples of the analyte. Recoveries ranged from $94.4 \%$ to $100.1 \%$ measured at $0.01 \sim 5 \mathrm{mg}$ $\mathrm{kg}^{-1}$ fortification level. This method was also shown to be highly precise with a relative standard deviation (RSD) of less than 5.9\%. The method detection limit (MDL) was calculated to $<0.006 \mathrm{mg} \mathrm{kg}^{-1}$. These data are within the accepted range for pesticide residue determination, 
showing that the extraction and analysis procedures are efficient for determination of chlorpyrifos in earthworm samples.

\section{Chlorpyrifos recovered from soil}

The amounts of chlorpyrifos recovered in soil are listed in Table 1. The extractable quantities of chlorpyrifos were dependent on aging time, individual extractant, and extraction method. For example, for the unaged target, the exhaustive Soxhlet extraction technique had the highest extraction efficiency, with the recovery of $97.6 \%$, and the mild extraction procedure with water was found to have the lowest recovery of $4.0 \%$. Recoveries of unaged insecticide using the mild extraction with methanol, methanol-water (9:1), and acetone-water (5:3) were 90.1\%, 93.0\%, and $94.0 \%$, respectively. Generally, the quantity extracted from the soil by each solvent or extraction method decreased as the test insecticide persisted in soil. After 120 days, for instance, only $76.0 \%$, $50.2 \%, 53.4 \%, 57.8 \%$, and $0.2 \%$ of chlorpyrifos initially added to soil was recovered with Soxhlet extraction, methanol extraction, methanol-water (9:1) extraction, acetone-water $(5: 3)$ extraction, and water extraction, respectively. Such declines indicate that organic compounds in soil become increasingly more resistant to extraction with time. Similar phenomena have been observed in other studies with dieldrin (Morrison et al., 2000), butachlor and myclobutanil ( $\mathrm{Yu}$ et al., 2005),phthalate congeners (e.g.,DBP and DEHP) (Hu et al.,2005), PAHs such as pyrene, anthracene, phenanthrene,chrysene, benz[a]anthracene and benzo(a)pyrene (Johnson et al., 2002; Tang et al., 2002), and DDT, DDE and DDD (Morrison et al., 2000; Fang et al., 2010).

The time-dependent reduction in extractability of a hydrophobic organic compound in the soil is governed by many factors including biodegradation and abiotic transport or transformation such as microbial degradation, adsorption, sequestration, and hydrolysis. In the present study, prior to and after the aging period of chlorpyrifos, samples of the irradiated soils were incubated on nutrient agar for 7 days, and no microbial growth was observed, suggesting that there were no microorganisms degrading chlorpyrifos in soil. Thus, the contribution of indigenous microorganisms to the decrease in extractability of chlorpyrifos in soil was neglectable. Presumably, the decline in extractability of chlorpyrifos with time mainly might result from the change of the combination states of the insecticide molecules in microsites within the soil matrix (e.g., a redistribution of chlorpyrifos molecules from weaker to stronger adsorption sites, sequestration, or covalent bond formation between the insecticide molecules and soil organic matter) (Hatzinger and Alexander, 1995; Alexander, 2000; Gevao et al., 2000; Reid et al., 2000a). In addition, the hydrolysis of chlorpyrifos in the soil solution also might result in the decrease in extractability of chlorpyrifos. For example, chlorpyrifos in the aqueous solution could be hydrolyzed into two metabolites, chlorpyrifos oxon ( $\mathrm{Wu}$ and Laird, 2003) and 3, 5, 6-trichloro-2pyridinol (Wu and Laird, 2002). Wu and Laird $(2002,2003)$ also found that the hydrolysis of chlorpyrifos in the aqueous solution was dependent on the initial concentration of chlorpyrifos and the chemistry of the aqueous solution.

\section{Uptake of chlorpyrifos by earthworms}

The quantities of chlorpyrifos detected in earthworms are shown in Table 2. The uptake of chlorpyrifos by earthworms also decreased with the aging of chlorpyrifos in soil. Concentrations of chlorpyrifos declined significantly $(p<0.05)$ after 
Table 1. Chlorpyrifos $\left(\mathrm{mg} \mathrm{kg}^{-1}\right)$ extracted from soil with methanol, methanol-water (9:1), acetone-water (5:3), and water.

\begin{tabular}{|c|c|c|c|c|c|c|}
\hline \multirow[t]{2}{*}{ Extraction } & \multicolumn{6}{|c|}{ Aging time (days) } \\
\hline & $\mathbf{0}$ & 7 & 14 & 30 & 60 & 120 \\
\hline Soxhlet & $4.88 \pm 0.09 \mathbf{a}$ & $4.60 \pm 0.12 \mathbf{b}$ & $4.20 \pm 0.07 \mathbf{c}$ & $3.98 \pm 0.15 \mathbf{d}$ & $3.90 \pm 0.08 \mathbf{d}$ & $3.8 \pm 0.09 \mathbf{d}$ \\
\hline Methanol & $4.54 \pm 0.13 \mathbf{a}$ & $4.27 \pm 0.08 \mathbf{b}$ & $3.56 \pm 0.16 \mathbf{c}$ & $3.19 \pm 0.12 \mathbf{d}$ & $3.02 \pm 0.15 \mathbf{d}$ & $2.51 \pm 0.21 \mathbf{e}$ \\
\hline Methanol-water(9:1) & $4.65 \pm 0.10 \mathbf{a}$ & $4.15 \pm 0.09 \mathbf{b}$ & $3.80 \pm 0.11 \mathbf{c}$ & $3.33 \pm 0.16 \mathbf{d}$ & $2.96 \pm 0.14 \mathbf{e}$ & $2.67 \pm 0.20 \mathbf{e}$ \\
\hline Acetone-water(5:3) & $4.70 \pm 0.10 \mathbf{a}$ & $4.40 \pm 0.09 \mathbf{b}$ & $3.81 \pm 0.12$ c & $3.39 \pm 0.05 \mathbf{d}$ & $3.20 \pm 0.10 \mathbf{e}$ & $2.89 \pm 0.17 \mathbf{e}$ \\
\hline Water & $0.20 \pm 0.04 \mathbf{a}$ & $0.053 \pm 0.01 \mathbf{b}$ & $0.044 \pm 0.02 \mathbf{b}$ & $0.026 \pm 0.01 \mathbf{b}$ & $0.020 \pm 0.01 \mathbf{C}$ & $0.008 \pm 0.02 \mathbf{d}$ \\
\hline
\end{tabular}

All data are the means \pm SD. Means in rows followed by the same letter are not statistically different $(p<0.05)$.

Table 2. Chlorpyrifos $\left(\mathrm{mg} \mathrm{kg}^{-1}\right)$ extracted from E. foetida and A. caliginosa.

\begin{tabular}{lcccccc}
\hline Earthworm & \multicolumn{5}{c}{ Aging time (days) } \\
\cline { 2 - 7 } & $\mathbf{0}$ & $\mathbf{7}$ & $\mathbf{1 4}$ & $\mathbf{3 0}$ & $\mathbf{6 0}$ & $\mathbf{1 2 0}$ \\
\hline E. foetida & $3.52 \pm 0.22 \mathbf{a}$ & $2.72 \pm 0.20 \mathbf{b}$ & $2.38 \pm 0.26 \mathbf{b c}$ & $2.19 \pm 0.21 \mathbf{c}$ & $2.01 \pm 0.43 \mathbf{~ c}$ & $1.89 \pm 0.35 \mathbf{~ c}$ \\
A. caliginosa & $3.32 \pm 0.15 \mathbf{a}$ & $2.35 \pm 0.23 \mathbf{~ b}$ & $2.05 \pm 0.20 \mathbf{b c}$ & $1.91 \pm 0.28 \mathbf{c}$ & $1.72 \pm 0.21 \mathbf{c d}$ & $1.35 \pm 0.24 \mathbf{d}$ \\
\hline
\end{tabular}

All data are the means $\pm \mathrm{SD}$. Means in rows followed by the same letter are not statistically different $(p<0.05)$. 
aging time of 7 days for both E. foetida and A.caliginosa, compared with unaged chlorpyrifos in soil. The decline rate in earthworm uptake of chlorpyrifos turned to be faded with aging. Such declines indicate that a certain portion of the compound become progressively less available to earthworms with time. A similar conclusion could be drawn from the studies of atrazine (Kelsey et al., 1997), dieldrin (Morrison et al., 2000), butachlor and myclobutanil (Yu et al., 2005), DBP and DEHP (Hu et al., 2005), PAHs including pyrene, anthracene, phenanthrene,chrysene,benz[a]anthracene and benzo(a)pyrene (Johnson et al., 2002; Tang et al., 2002) , $\mathrm{HCB}(\mathrm{Gao}, 2009)$, and DDT, DDE and DDD (Morrison et al., 2000; Fang et al., 2010).

Concentrations of chlorpyrifos were always higher in E. foetida than in $A$. caliginosa. Based on the result provided by the paired t-test, the effect of specific species on availability of chlorpyrifos in soil to earthworms was statistically significant $(p<0.05)$, suggesting the test insecticide is differently available to the two earthworm species involved. The findings presented herein are in agreement with the results of $\mathrm{Yu}$ et al. (2005) who found that concentrations of the herbicide butachlor and the fungicide myclobutanil with aging of $0 \sim 60$ days in $E$. foetida were always higher than ones in A. caliginosa. Kelsey and White (2005) also demonstrated that amounts of weathered p, p'-DDE uptaken by $E$. foetida were significantly higher than uptake by the anecic species Lumbricus terrestris. In an earlier study performed by Haimi et al. (1992), concentrations of chlorophenols in the endogeic specie $A$. caliginosa were found to be higher than in L. terrestris. However, Haque and Ebing (1988) got opposite results. In their experiments $L$. terrestris accumulated three times more pentachlorophenolresidues than did A.caliginosa. These results suggest that there are speciesrelated differences in availability of an organic chemical to earthworms. Thus, selection of an appropriate species for bioavailability assessment is imperative. A protocol employing $E$. foetida for use in screening potential toxicity of hazardous waste sites has been adopted by the United States Environmental Protection Agency (USEPA). However, E. foetida is a compost-dwelling species. Its ecological representativeness for soil-dwelling species may be questioned. According to our results and those previously published by others, E. foetida might not be a suitable species for such tests. In comparison, soil-dwelling species such as A. caliginosa or L. terrestris might be more appropriate.

There are a number of possible explanations for species-related differences in bioavailability of organic chemicals to earthworms, which centre on the chemical, physical and biological factors. The particular physiological behavior profiles of earthworms, such as capacity for uptake, elimination, and metabolism, are compelling factors. In the present study, all organisms were depurated under the same conditions and soil depuration in gastrointestinal tracts was exhaustive, showing no discrepancy in depuration of chlorpyrifos from earthworm gastrointestinal tracts. Compared to $A$. caliginosa living near the surface soils, $E$. foetida living in compost has relatively high body-lipid contents. $E$. foetida is likely to selectively ingest the soil of high organic matter that is more readily associated with organic chemicals. As a result, soil-associated chlorpyrifos might be readily incorporated into the gastrointestinal tract. After being ingested, chlorpyrifos could be easily accumulated in the E. foetida tissues due to its high $\log \mathrm{K}_{\mathrm{ow}}$ (4.7). Besides differences in behavior or feeding activity, the metabolizing enzymes in 
earthworms also might contribute to species-specific differences in chlorpyrifos accumulation between the two earthworm species. There are a large number of enzymes (e.g., carboxylesterases (CEs), phosphotriesterases (PTEs), CYP450s, etc.) in a multitude of species (from mammals to microorganisms) involved in the detoxification of organophosphorus pesticides (OPP) through hydrolysis or redox (Jokanovic, 2001; Sogorb and Vilanova, 2002). For instance, some soil-dwelling earthworms such as L.terrestris secreted actively CEs into the gut lumen (Sanchez-Hernandez et al., 2009). Maxwell (1992) found that CEs were irreversibly bound (1:1 ratio) to OPP, and Vejares et al. (2010) further showed that gut CEs of L. terrestris could offered an efficient biochemical barrier against chlorpyrifos uptake from the ingested contaminated soil. In addition, the difference between bioaccumulation of chlorpyrifos also might be related to the different microorganisms present in the guts of earthworms. Parle (1963) found that, for example, total counts of microorganisms were dependent on species-specific of earthworms. Total counts of bacteria in the guts decreased in the order of $A$. longa $>$ L.terrestris $>A$. caliginosa, while total counts of both fungi and actinomycetes in the guts decreased in the order of $A$. longa $>A$. caliginosa $>$ L. terrestris. It is, therefore, not surprising that there was the difference between concentrations of chlorpyrifos in both $E$. foetida and $A$. caliginosa, as was opposite conclusion between findings of Haimi et al. (1992) and Haque and Ebing (1988). These should be explained by the combined effects of the biotic and abiotic factors and should be the result of the balance between these different factors.

\section{Relationship between extractability and bioavailability}

The variation in the extractability of chlorpyrifos with time is presented in Table 1. The extractable amounts of chlorpyrifos for each extractant or extraction method decreased as aging time increased. The uptake of chlorpyrifos by both E.foetida and A.caliginosa also decreased with the residence time of the insecticide in soil (Table 2). The similar decrease patterns of extractability and bioavailability of chlorpyrifos with time show a prima facie that they might be linked. To test this hypothesis, the linear regression analyses between extractability and bioavailability were performed. As expected, the quantity of chlorpyrifos extracted by extractants from soil was significantly correlated $(p<0.01)$ with uptake by E. foetida. The correlation coefficients (r) ranged from 0.934 to 0.973 (Table 3). Likewise, significant correlations $(p<0.01)$ were also obtained between amounts of chlorpyrifos accumulated by A.caliginosa and extracted by solvents, with $\mathrm{r}$ values of 0.933 0.956 (Table 3).

The significant correlations between extractability and bioavailability show that these extraction techniques would be efficient for predicting the availability of chlorpyrifos to earthworms. However, as a predictor of bioavailability, the extractable amount of an extractant for a compound should closely represent the bioavailable fraction of the compound in soil except for the reasonable relationship between bioavailability and extractability (Kelsey et al., 1997; Lanno et al., 2004; $\mathrm{Yu}$ et al., 2005). Chlorpyrifos extracted from soil by the mild extraction with methanol and methanol-water $(9: 1)$ was much closer to the available fraction of chlorpyrifos to the tested animal $E$. 
Table 3. Correlation coefficients (r) and regression equations between extractability(x) and bioavailability(y) of Chlorpyrifos.

\begin{tabular}{lccc}
\hline Extractability & Bioavailability & Regression equation & r \\
\hline Soxhlet & E. foetida & $\mathrm{y}=1.362 \mathrm{x}-3.306$ & $0.973^{* *}$ \\
& A. caliginosa & $\mathrm{y}=1.013 \mathrm{x}-4.260$ & $0.953^{* *}$ \\
Methanol & E. foetida & $\mathrm{y}=0.725 \mathrm{x}-0.096$ & $0.934^{* *}$ \\
& A. caliginosa & $\mathrm{y}=0.818 \mathrm{x}-0.759$ & $0.933^{* *}$ \\
Methanol-water (9:1) & E. foetida & $\mathrm{y}=0.763 \mathrm{x}-0.290$ & $0.951^{* *}$ \\
& A. caliginosa & $\mathrm{y}=0.860 \mathrm{x}-0.974$ & $0.949^{* *}$ \\
Acetone- water (5:3) & E. foetida & $\mathrm{y}=0.803 \mathrm{x}-0.543$ & $0.946^{* *}$ \\
A. caliginosa & $\mathrm{y}=0.898 \mathrm{x}-1.234$ & $0.937^{* *}$ \\
Water & E. foetida & $\mathrm{y}=8.071 \mathrm{x}+1.979$ & $0.958^{* *}$ \\
& A. caliginosa & $\mathrm{y}=9.908 \mathrm{x}+1.584$ & $0.956^{* *}$ \\
\hline
\end{tabular}

** represent $p<0.01$.

foetida, respectively (Tables 1 and 2). The corresponding equation for the regression line was $\mathrm{y}=0.725 \mathrm{x}-0.096$ and $\mathrm{y}=0.763$ $\mathrm{x}-0.290$ (Figure 1), respectively. Similarly, the uptake of chlorpyrifos by earthworm A.caliginosa approximated the amount recovered by the non-exhaustive extraction with methanol and methanolwater (9:1), respectively. The corresponding linear regression equation was $\mathrm{y}=0.818 \mathrm{x}-0.759$ and $\mathrm{y}=0.860 \mathrm{x}-$ 0.974 (Figure 2), respectively. The extractable amounts of other three extraction methods were not closer the portions available to E. foetida or A.caliginosa. Chlorpyrifos recovered by the non-exhaustive or mild extraction with methanol or methanol-water $(9: 1)$ may reflect the bioavailability of chlorpyrifos more factually. Accordingly, the mild extraction with methanol or methanol-water (9:1) might be preferable as a predictor of the bioavailability of aged or unaged chlorpyrifos in soil to earthworms.
Bioavailability is an important consideration in the risk assessment of soil contaminants and in the selection of appropriate remediation technologies for polluted sites. Nevertheless, current procedures for analyzing organic pollutants that have persisted in soil do not accurately predict the bioavailability of these toxic chemicals in biota. Exhaustive extraction, for example, Soxhlet with methanol may overestimate the exposure of animals or plants to pollutants because it often overestimates the concentrations that are actually bioavailable. It is thus important, for regulatory purposes, to establish the feasible assay procedures to measure the bioavailable fractions of pollutants. The results herein show that the non-exhaustive extraction techniques with methanol, methanolwater (9:1), and acetone-water (5:3) might be useful means for predicting chlorpyrifos bioavailability to earthworms. 

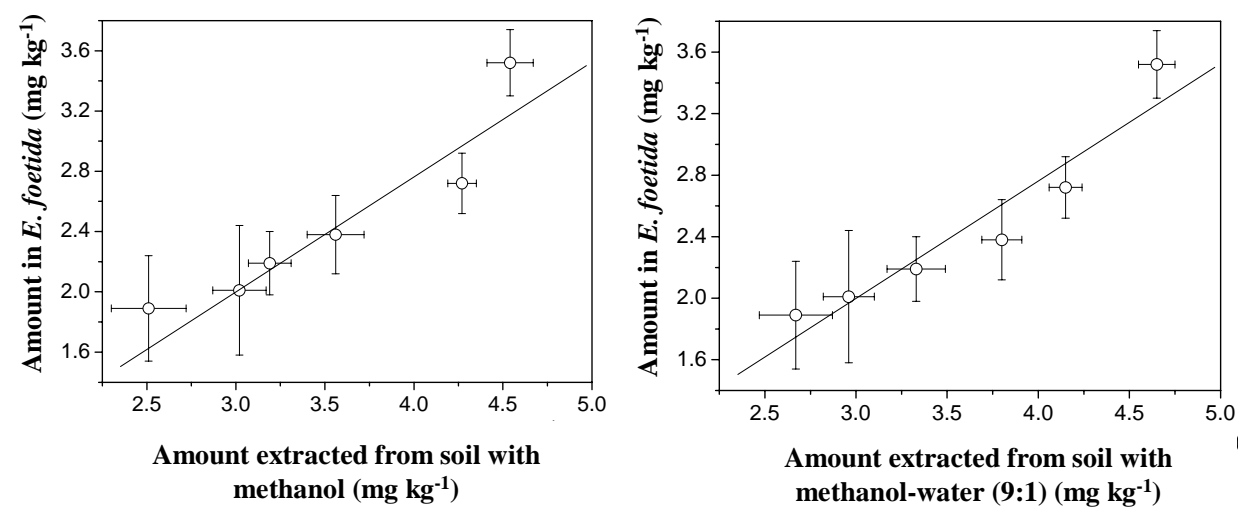

Figure 1. Correlation between the fraction of chlorpyrifos in soil available to E. foetida and amount extracted by mild extraction with methanol and methanol-water (9:1). Error bars indicate $\pm \mathrm{SD}$.
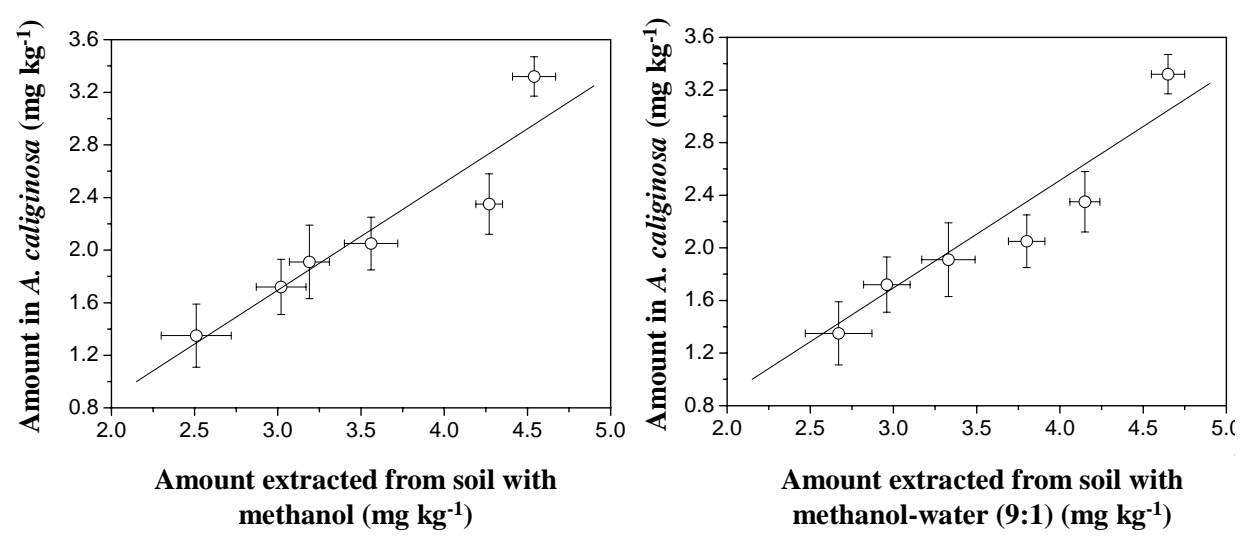

Figure 2. Correlation between the fraction of chlorpyrifos in soil available to $A$. caliginosa and amount extracted by mild extraction with methanol and methanol-water (9:1). Error bars indicate \pm SD.

\section{CONCLUSIONS}

The results presented here show that the extractability of chlorpyrifos decreased with its residence time in soil. The amount of aged and unaged chlorpyrifos recovered from soil was dependent on the individual extractant and extraction method. The bioavailability of chlorpyrifos also decreased with time. The concentrations of chlorpyrifos in $E$. foetida were significantly higher than in 
A. caliginosa, suggesting that the availability of the soil-sequestered chlorpyrifos was a species-dependent process. The extractability of chlorpyrifos by chemical solvents was significantly correlated with its bioavailability to $E$. foetida and A.caliginosa, showing that the use of the five chemical extraction procedures would be useful for predicting bioavailability of chlorpyrifos in soil. Nevertheless, the data presented herein represent merely the results of a feasibility study for predicting the bioavailability of the target insecticide chlorpyrifos because there were only two species of test organisms, one soil, and five solvent systems tested in the present study. More test organisms, soils, exposure concentrations, and solvent systems with different characteristics will be involved in the future work.

\section{ACKNOWLEDGMENTS}

This research was supported by the National Hi-Tech Research and Development Program (863) of China (2007AA06Z306), and the National Natural Science Foundation of China (No.30771254).

\section{REFERENCES}

Alexander, M. 2000. Aging, bioavailability, and overestimation of risk from environmental pollutants. Environ. Sci. Technol. 34(20), 42594265 .

Chung, N., Alexander, M. 1998. Differences in sequestration and bioavailability of organic compounds aged in dissimilar soils. Environ. Sci. Technol. 32(7), 855-860.

Cuypers, C., Grotenhuis, T., Joziasse, J., Rulkens, W. 2000. Rapid persulfate oxidation predicts PAH bioavailability in soils and sediments. Environ. Sci Technol. 34(10), 20572063
Fang, H., Chu, X.Q., Wang, X.G., Pang, G.H., Yu, Y.L. 2010. Using matrix solid-phase microextraction (matrix-SPME) to estimate bioavailability of DDTs in soil to both earthworm and vegetables. Arch. Environ. Contam. Toxicol. 58(1), 62-70.

Fang, H., Yu, Y.L., Wang, X.G., Chu, X.Q., Pan, X.D., Yang, X.E. 2008. Effects of repeated applications of chlorpyrifos on its persistence and soil microbial functional diversity and development of its degradation capability. Bull. Environ. Contam. Toxicol. 81, 397-400.

Fang, H., Yu, Y. L., Wang, X., Shan, M., Wu, X. M., Yu, J. Q. 2006. Dissipation of chlorpyrifos in pakchoi-vegetated soil in a greenhouse. J.Environ. Sci. 18 (4), 760-764.

Gao, H.J. 2009. Bioaccumulation of hexachlorobenzene in Eisenia foetida at different aging stages. J.Environ. Sci. 21(7), 948-953.

Gevao, B., Semple, K.T., Jones, K.C. 2000. Bound pesticide residues in soils: a review. Environ.Pollut.108 (1): 3-14.

Haimi, J., Salminen, J., Huhta, V., Knuutinen, J., Palm, H. 1992. Bioaccumulation of organochlorine compounds in earthworms. Soil Biol. Biochem. 24(12), 1699-1703.

Haque, A., Ebing, W. 1988. Uptake and accumulation of pentachlorophenol and sodium pentachlorophenate by earthworms from water and soil. Sci. Total. Environ.68, 113125.

Hatzinger, P.B., Alexander, M. 1995. Effect of ageing of chemicals in soil on their biodegradability and extractability. Environ. Sci. Technol. 29(2), 537-545.

Hawthorne, S.B., Grabanski, C.B. 2000. Correlating selective supercritical-fluid extraction with bioremediation behavior of PAHs in a field treatment plot. Environ. Sci. Technol. 34(19), 4103-4110.

Hu, X.Y., Wen, B., Zhang, S.Z., Shan, X.Q. 2005. Bioavailability of phthalate congeners to earthworms (Eisenia fetida) in artificially contaminated soils. Ecotoxicol. Environ. Saf. 62(1), 26-34.

Johnson, D.L., Jones, K.C., Langdon, C.J., Piearce, T.G., Semple, K.T. 2002. Temporal changes in earthworm availability and extractability of polycyclic aromatic hydrocarbons in soil. Soil Biol. Biochem. 34(9), 1363-1370. 
Jokanovic, M. 2001. Biotransformation of organophosphorus compounds. Toxicology 166(3), 139-160.

Kelsey, J.W., Kottler, B.D., Alexander, M. 1997. Selective chemical extractants to predict bioavailability of soil-aged organic chemicals. Environ. Sci. Technol. 31(1), 214-217.

Kelsey, J.W., White, J.C. 2005. Multi-species interactions impact the accumulation of weathered 2, 2-bis (p-chlorophenyl)-1, 1dichloroethylene (p,p'-DDE) from soil. Environ. Pollut.137 (2), 222-230.

Lanno, R., Wells, J., Conder, J., Bradham, K., Basta, N. 2004. The bioavailability of chemicals in soil for earthworms. Ecotoxicol. Environ. Saf. 57 (1), 39-47.

Lu, R.K (Ed). 2000. Methods of soil and agrochemistry analysis. Chinese Agricultural Science and Technology Press, Beijing (in Chinese).

Maxwell, D.M. 1992. The specificity of carboxylesterase protection against the toxicity of organophosphorus compounds. Toxicol. Appl. Pharmacol. 114, 306-312.

Menchai, P., Zwieten, L.V., Kimber, S., Ahmad, N., Rao, P.S.C., Hose, G. 2008. Bioavailable DDT residues in sediments: laboratory assessment of ageing effects using semi-permeable membranedevices. Environ. Pollut. 153(1), 110-118.

Morrison, D.E., Robertson, B.K., Alexander, M. 2000. Bioavailability to earthworms of aged DDT, DDE, DDD, and dieldrin in soil. Environ. Sci. Technol. 34(4), 709-713.

Ngan, C.K., Cheah, U.B., Wan Abdullah, W.Y., Lim, K.P., Ismail, B.S. 2005. Fate of chlorothalonil, chlorpyrifos and profenofos in a vegetable farm in cameron Highlands, Malaysia. Water Air Soil Pollut. 5, 125-136.

Parle, J.N. 1963. Micro-organisms in the intestines of earthworms. J. Mthobiol. 31, 1-11.

Racke, K.D., Steele, K.P., Yoder, R.N., Dick, W.A., Avidov, E. 1998. Factors affecting the hydrolytic degradation of chlorpyrifos in soil. J. Agri. Food Chem. 44(6), 1582-1592.
Reid, B.J., Jones, K.C., Semple, K.T. 2000a. Bioavailability of persistent organic pollutants in soils and sediments--a perspective on mechanisms, consequences and assessment. Environ. Pollut. 108(1), 103-112.

Reid, B.J., Stokes, J.D., Jones, K.C., Semple, K.T. 2000b. Nonexhaustive cyclodextrin-based extraction technique for the evaluation of PAH bioavailability. Environ. Sci. Technol. 34(15), 3174-3179.

Sanchez-Hernandez, J.C., Mazzia, C., Capowiez, Y., Rault, M. 2009. Carboxylesterase activity in the earthworm gut content: potential (eco) toxicological implications. Comp. Biochem. Physiol. C 150, 503-511.

Singh, B.K., Walke, A., Morgan, J.A.W., Wright, D.J. 2003. Effects of soil $\mathrm{pH}$ on the biodegradation of chlorpyrifos and isolation of a chlorpyrifos-degrading bacterium. Appl. Environ. Microbiol. 69(9), 5198-5206.

Sogorb, M.A., Vilanova, E. 2002. Enzymes involved in the detoxification of organophosphorus, carbamate and pyrethroid insecticides through hydrolysis. Toxicol. Lett. $128,215-228$.

Tang, J., Alexander, M. 1999. Mild extractability and bioavailability of aged and unaged polycylic aromatic hydrocarbons in soil. Environ. Toxicol. Chem. 18(12), 27112714

Tang, J., Liste, H.H., Alexander, M. 2002. Chemical assays of availability to earthworms of polycyclic aromatic hydrocarbons in soil. Chemosphere 48(1), 35-42.

Tao, S., Guo, L.Q., Wang, X. J., Liu, W. X., Ju, T. Z., Dawson, R., Cao, J., Xu, F. L., Li, B. G. 2004. Use of sequential ASE extraction to evaluate the bioavailability of DDT and its metabolites to wheat roots in soils with various organic carbon contents. Sci. Total. Environ. $320(1), 1-9$.

Trimble, T.A., You, J., Lydy, M.J. 2008. Bioavailability of PCBs from field-collected sediments: application of Tenax extraction and matrix-SPME techniques. Chemosphere 71(2), 337-344. 
Vejares, S.G., Sabat, P., Sanchez-Hernandez, J.C. 2010.Tissue-specific inhibition and recovery of esterase activities in Lumbricus terrestris experimentally exposed to chlorpyrifos. Comp. Biochem. Physiol. C.151, 351-359.

Vischetti, C., Coppola, L., Monaci, F., Cardinali, A., Castilloc, M.D. P. 2007. Microbial impact of the pesticide chlorpyrifos on Swedish and Italian biobeds. Agron. Sustain. Dev. 27(3), 267-272.

Wu, J.Q., Laird, D.A. 2002. Hydrolysis of chlorpyrifos in aqueous and colloidal systems. Israel J.Chem. 42(1), 99-107.

Wu, J.Q., Laird, D.A. 2003. Abiotic transformation of chlorpyrifos to chlorpyrifos oxon in chlorinated water. Environ. Toxicol. Chem.22(2), 261-264.
Yucel, U., Ylim, M., Gozek, K., Helling, C. S., Sarykaya, Y. 1999. Chlorpyrifos degradation in Turkish soil. J. Environ. Sci. Health B-Pestic. 34(1), 75-95.

Yu, Y.L., Wu, X.M., Li, S. N., Tan, Y.J., Fang, H., Yu, J.Q. 2005. Bioavailability of butachlor and myclobutanil residues in soil to earthworms. Chemosphere 59(7), 961-967.

Yan, Z.M., Zhai, X.G., Meng, Y.G. 2000. Species and characteristics of earthworms. In: Earthworms. Traditional Chinese Medicine and Material Medical Press, Beijing (in Chinese), pp. 67-68, 81-82.

Zhao, X., Voice, T.C. 2000. Assessment of bioavailability using a multicolumn system. Environ. Sci. Technol. 34(8), 1506-1512. 